\title{
SEJARAH PEMIKIRAN HUKUM AHMAD BIN HANBAL
}

\author{
Oleh: \\ Husnul Khatimah \\ Fakultas Syariah STAIN Nurul Huda Kapongan \\ Hkhatimah257@gmail.com
}

\begin{abstract}
:
Imam Ahmad bin Hanbal is the fourth Imam of the fuqoha 'Islam. Descendants of Ahmad bin Hanbal met with the descendants of Rasulullah SAW on Mazin bin Mu'ad bin 'Adnan. Ahmad bin Hanbal was born in Baghdad Rabiul Awwal $164 \mathrm{H} / 780 \mathrm{AD}$ He is a figure of a character who has noble character, high character, simple, populist and has high Islamic commitment. His love of hadith and allegiance to Prophet Muhammad SAW to be paid with physical and non-physical sacrifices is an added value to be respected. In addition to hadith and fiqh experts, he is a productive scientist, it is seen from some of his works that we can still find today. His famous book is Musnad, which is one of the most important and valuable heritages for formulation of contemporary thought and problem solving. Book of Musnad is also one of the most widely read references to date. Method of writing this book is based on names of companions of the Prophet who narrated the hadith. To Consider the Qur'an as a source of Islamic law, Ahmad ibn Hanbal argues that the Qur'an is a fundamental source of Islam, followed by sunnah, but according to him as Sunnah has a position that is equally strong in addition to the Qur'an. In interpretation of Qur'anic verse, Imam Ahmad really attaches importance to interpretation that comes from sunnah.
\end{abstract}

Key Words: Sejarah Pemikiran Hukum, Ahmad bin Hambal dan Hukum Islam

\section{A. Pendahuluan}

Islam adalah agama yang sempurna, Islam mengatur seluruh aspek dan sendi-sendi kehidupan para pemeluknya, hal itu tercakup dalam kitab suci umat Islam yang menjadi pedoman dan rujukan terhadap setiap fenomena serta permasalahan yang muncul, yakni al Quran dan hadith sebagai representatif dari al Quran itu sendiri, namun aturan yang terdapat dalam al Quran maupun hadith tersebut masih bersifat global belum menyentuh terhadap permasalahan yang parsial, sehingga zaman sekarang ini banyak bermunculan permasalahan tentang kebenaran hukum-hukum Islam, hal ini lebih disebabkan oleh adanya interpretasi 
terhadap nas\} al Qur'an maupun hadith yang berbeda serta kemungkinan adanya perbedaan metode intinbath hukum yang dilakukan.

Fenomena yang demikian itu, mengakibatkan munculnya perdebatan-perdebatan dikalangan masyarakat yang fanatik terhadap aliran / madzhab tertentu terhadap permasalahan yang hakikatnya bukan permasalahan substansial. Adapun yang perlu menjadi perhatian, bahwasanya para Imam Madzhab memiliki metode intinbath hukum tersendiri dalam menetapkan suatu hukum, walaupun dasar yang digunakan adalah sama, yakni al Qur'an dan as sunnah. Namun apabila dalam suatu masalah tidak ada penyelesaian hukum di dalam keseluruhan dasar hukum tersebut, maka mereka berijtihad untuk mencari penyelesaian hal tersebut, maka dalam ijtihad inilah terjadi penetapan hukum yang berbeda, dikarenakan masing-masing Imam menggunakan metode yang berbeda.

Pada makalah ini kami mencoba menguraikan tentang Imam madzhab keempat yakni Imam Ahmad bin Hanbal, yang biasa dikenal oleh masyarakat luas sebagai seorang yang ahli di bidang hadith dan juga sekaligus ahli dalam bidang ilmu fiqh. Diharapkan pembahasan ini dapat digunakan sebagai bahan tela'ah dan khazanah pengetahuan tentang metode serta gaya khas seorang ulama' madzhab sekaliber imam Ahmad bin Hanbal, dimaksudkan agar pembaca mampu memahami corak serta style istinbath yang dilakukannya.

\section{B. Imam Ahmad bin Hanbal}

\section{Riwayat Hidup dan Latar Belakang Pendidikan Ahmad bin} Hanbal

Nama lengkapnya adalah Ahmad bin Muhammad bin Hanbal bin Asad bin Idris bin Abdullah bin Hasan As-Syaibany. ${ }^{1}$ yang masih merupakan keturunan dengan Rasulullah S.A.W, pada Mazin bin Mu'ad bin 'Adnan. Nama Hanbal sebetulnya ialah nama datuknya / kakeknya dan menjadi panggilannya karena dalam rangka menghormati keturunannya. Beliau dilahirkan di Baghdad pada bulan Robiu'l Awal Tahun 164 H. ${ }^{2}$

Ketika beliau masih kecil, ayahnya meninggal dunia dengan hanya meninggalkan sedikit harta untuk kehidupan keluarganya. Semenjak kematian ayahnya ibunya tidak menikah lagi. Hal ini dilakukan dengan tujuan agar ia bisa memfokuskan perhatian kepada Ahmad sehingga bisa

1 Huzaemah Tahido Yanggo, Pengantar Perbandingan Madzhab (Jakarta: Gaung Persada, 2011), hlm. 154.

2 Muhammad Abu Zahrah, Ibn Hanbal (Kairo: Dar al Fikr al Araby, 1997), hlm. 15.

$160 \mid$ JURNAL LISAN AL-HAL 
tumbuh sebagaimana yang ia harapkan. Ibu beliau bernama Safiyyah binti Maimunah binti Abdul Malik as Syaibany. ${ }^{3}$

Sejak kecil beliau memang menunjukkan minat yang mendalam terhadap ilmu pengetahuan, hal ini dapat terlihat dari kebiasaan beliau yakni selalu membawa tinta dan kertas kemana saja beliau pergi, untuk menulis sesuatu yang dirasakan bermanfaat baginya. Pada saat itu, Baghdad merupakan kota pusat ilmu pengetahuan, sehingga beliau tidak melewatkan kesempatan tersebut dengan memperdalam ilmu pengetahuan, beliau memulai dengan belajar menghafal al-Quran, kemudian belajar bahasa Arab, dan hadith. ${ }^{4}$

Imam Ahmad bertubuh tidak terlalu tinggi dan tidak terlalu pendek serta berkulit sawo matang. ${ }^{5}$ Beliau mulai belajar hadith pada tahun $179 \mathrm{H}$ ketika berusia 16 tahun, dan untuk pertama kalinya beliau belajar hadith pada Abu Yusuf. ${ }^{6}$ Abu Yusuf adalah seorang ahl al-ra'yi dan salah satu sahabat Abu Hanifah. Abu Yusuf juga seorang hakim agung pada pemerintahan Bani Abbasiyah.

Untuk memperdalam ilmu, beliau pergi ke Basrah untuk beberapa kali, disanalah beliau bertemu dengan Imam Syafi'i, kemudian beliau pergi menuntut ilmu ke Kufah, Bashrah, Yaman, Syam, Mesir, Makkah dan Madinah. Diantara guru-guru beliau adalah Sufyan bin Uyainah, Yusuf alHasan Bin Ziad, Husyaim, Umair, Ibnu Humam, Ibnu Abbas, Hammam Bin Kholid, Ismail Bin Aliyyah, Muzaffar Bin Mudrik, Walid Bin Muslim, Muktamar Bin Sulaiman, Abu Yusuf Al-Qodhi, Yahya Bin Zaidah, Ibrahim Bin Said, Muhammad Bin Idris As-Syafii, Abdurrozaq Bin Humam dan Musa Bin Thoriq, dari guru-gurunya inilah beliau belajar Ilmu Fiqh, Hadith, Tafsir, Kalam, Ushul, dan bahasa Arab. ${ }^{7}$

Kondisi kehidupan yang sejak awal sangat sederhana, menjadi salah satu pendorong bagi Ahmad untuk belajar dengan sungguh-sungguh. Beliau mempunyai obsesi untuk bisa segera mengurangi beban sang ibu. Ahmad menikah dan memiliki dua orang putera yang terkenal dalam

3 Ahmad Asy Syurbasy, Sejarah dan Biografi Empat Imam Madzhab (Jakarta: Amzah, 2008), hlm. 192.

4 Abu Zubair, "Biografi Imam Ahmad bin Hanbal", dalam http://www.wordpress.com (22 Oktober 2016), hlm. 1.

5 www.nippontori.multiply.com"Biografi Imam Ahmad bin Hanbal" (21 Oktober 2016), hlm. 1.

6 Ahmad Asy Syurbasy, Sejarah dan Biografi Empat Imam Madzhab (Jakarta: Amzah, 2008), hlm. 193. hlm. 82 .

${ }^{7}$ Hafidz Dasuki, Ensiklopedi Islam, Jilid III, (Jakarta: Ichtiar Baru Van Hoeve, 1993),

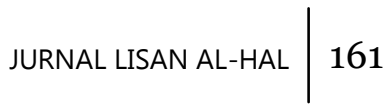


bidang hadith yaitu S\{alih dan Abdullah. Kedua puteranya banyak menerima hadith dari sang ayah.

Ahmad seorang ilmuwan yang produktif. Beliau banyak menulis kitab di antaranya ialah kitab al-'Ilal, al-Tafsir, al-Nasikh wa al-Mansukh, kitab al-Zuhd, al-Masa'il, kitab Fadhail al-Shahabah, kitab al-Asyribah, kitab al-Fara'id, al-Manasik, kitab al-Iman, Tha'at al-Rasul, dan kitab al-Ra'd 'ala al-Jahmiyah. Kitabnya yang paling agung dan termasyhur ialah al-Musnad karena di dalamnya memuat lebih dari dua puluh tujuh ribu hadith. ${ }^{8}$

\section{Kehidupan Politik Pada Masa Ahmad bin Hanbal}

Imam Ahmad bin Hanbal hidup pada zaman pemerintahan al Mahdi, al Makmun, al Mu'tasim, al Wathiq dan al Mutawakil. Pada masa pemerintahan al Makmun dari dinasti Abbasiyah, beliau menjadi korban mihna $^{9}$ dan sempat dipenjara karena tidak sependapat dengan penguasa pada waktu itu.

Kaum Mu'tazilah mempunyai pengaruh yang besar terhadap pemerintahan khalifah al Ma'mun, al Mu'tasim dan al Wathiq, karena kaum Mu'tazilah adalah penasihat resmi otokrasi Abbasiyah. Para khalifah tersebut menerima pandangan Mu'tazilah sebagai akidah dan memaksakannya pada seluruh kaum muslim. Namun Imam Ahmad selalu melakukan perlawanan terhadap dogma-dogma agama dan politik yang disebarkan oleh kekhalifahan daulah Abbasiyah yang menurut Imam Ahmad tidak berdasarkan kepada Al Qur'an dan hadith. Bahkan para penguasa mengeksploitasi agama sebagai alat untuk mempertahankan kekuasaan dan hak-hak istimewa mereka dalam perekonomian. ${ }^{10}$

Di bawah kepemimpinan khalifah al Mu'tasim, beliau tabah menerima hukuman fisik dan penjara. Khalifah Mu'tasim berulangkali mendesak Ibn Hanbal agar menerima akidah Mu'tazilah, akan tetapi beliau menolak dengan tegas. Hal inilah yang membuat beliau dihukum dengan sangat keji, sehingga sebagian tulang sendinya lepas. Banyak para ahli hadith, ahli fiqh, sarjana dan hakim dipaksa untuk tunduk pada dogma resmi bahwa al Qur'an adalah ciptaan dan bukan firman Allah.

Pada saat pemerintahan al Mutawakkil (232 H/846 M), ia menarik dekrit resmi mengenai khalq al Qur'an dan Imam Ahmad pun dibebaskan

${ }^{8}$ www.wikipedia.org"Ahmad bin Hanbal" (21 Oktober 2016), hlm. 5.

9 Dalam sejarah Islam, Mihnah yang dilakukan oleh pemerintahan al Makmun untuk menguji keyakinan para ulama' hadith mengenai hakikat al Qur'an, apakah diciptakan (makhluk) atau bukan.

${ }^{10}$ www. blogspot.com"Pemikiran Ahmad bin Hanbal" (22 Oktober 2016), hlm. 4.

162 JURNAL LISAN AL-HAL 
dari penjara. ${ }^{11}$ Beliau selalu menghindari kantor-kantor pemerintahan. Beliau juga menolak bantuan apapun dari pemerintah. Ketika suatu hari Harun al Rasyid menawarkan jabatan hakim di Yaman atas dasar rekomendasi dari Imam Syafi'I, Ahmad dengan keras menolaknya. ${ }^{12}$ Ahmad bin Hanbal meninggal di Bagdad pada hari Jum'at bulan Rabiul Awal tahun $241 \mathrm{H}$ atau bertepatan dengan $855 \mathrm{M}$, ketika berusia 77 tahun.

\section{Latar Belakang Metode Ahmad ibn Hanbal}

Pada tahun 195 H Ahmad belajar fiqh dan ushul fiqh pada Imam Syafi'i yang pada waktu itu berada di Hijaz. ${ }^{13}$ Di Hijaz pula beliau belajar pada Imam Malik dan Imam al-Laits ibn Sa'ad al-Misri. Dalam pencarian hadith beliau juga pergi ke Yaman, kepada Abdurraziq bin Hammam dan ke daerah-daerah lain seperti Khurasan dan Persia.

Ahmad menganggap Imam Syafi'i sebagai guru besarnya, oleh karena itu dalam pemikiran beliau banyak dipengaruhi oleh Imam Syafi'i. Hal ini dapat diketahui dari kata-kata Ahmad ibn Hanbal ketika beliau sudah menjadi Imam yang besar, beliau berkata "Apabila saya ditanya tentang sesuatu yang tidak saya jumpai kabar (yakni hadis dan atsar para sahabat) yang menjelaskannya, maka saya berpegang kepada pendapat Imam Syafi'i."

Meskipun pemikiran dan metode Ahmad banyak dipengaruhi oleh Imam Syafi'i, akan tetapi warna fiqh yang dihasilkannya kadang berbeda dengan Imam Syafi'i, hal tersebut sangat mungkin karena beliau lebih menguasai hadith daripada Imam Syafi'i. Dalam masalah yang sama Ahmad bisa berbeda pendapat dengan Imam Syafi'i, karena beliau mempunyai hadith tentang masalah tersebut, sementara Imam Syafi'i tidak.

Karyanya yang monumental, Musnad Ahmad juga jauh lebih banyak memuat hadith, sementara karya Imam Syafi'i adalah percampuran keduanya. Bisa dikatakan posisi Ahmad berada di antara Imam Syafi'i dan Imam Maliki. Dengan demikian meskipun beliau banyak dipengaruhi oleh Imam Syafi'i, banyak pula warna-warna Maliki dalam fiqhnya. Dalam metodenya beliau juga menggunakan qiyas dan istihsan serta mempunyai kecenderungan tekstualis serta mengembalikan masalah kepada hadith dan athar. ${ }^{14}$

${ }^{11}$ Ahmad Asy Syurbasy, Sejarah dan Biografi Empat Imam Madzhab (Jakarta: Amzah, 2008), hlm. 214.

${ }^{12}$ www. blogspot.com "Pemikiran Ahmad bin Hanbal" (22 Oktober 2016), hlm. 5.

${ }^{13}$ Muhammad Ibn Ulwy al Maliki al Hasani, al Minhaj al Latihf, hlm. 280.

${ }^{14}$ Huzaemah Tahido Yanggo, Pengantar Perbandingan Madzhab (Jakarta: Gaung 
Ahmad bin Hanbal bukan hanya seorang ahli hadith dan fiqh, beliau juga seorang sufi yang dipengaruhi oleh pemikiran dan teladan dari seorang sufi besar, Hasan al-Basri (wafat 110 H/728 M) dan Ibrahim ibn Adham (wafat $170 \mathrm{H} / 786 \mathrm{M}$ ). Keduanya memberikan pengaruh besar dalam memberikan jalan dan metode untuk mencapai hidup yang sejati dan kewajiban-kewajiban yang benar terhadap Allah. ${ }^{15}$

\section{Pemikiran Ahmad bin Hanbal}

Beliau memberikan kontribusi yang sangat besar terhadap umat Islam, diantara adalah; Beliau mengumpulkan dan menyusun hadith secara rapi dan sempurna mengikutkan nama-nama sahabat Nabi Muhammad SAW yang meriwayatkannya satu persatu dalam kitab Musnadnya. Sifat ketelitian dan kesungguhan Imam Ahmad bin Hanbal menyelidiki hadith-hadith Nabi Muhammad SAW dapat membersihkan hadith-hadith dari pemalsuan. Usaha ini juga menjadikan hadith dan sunah Rasulullah terpelihara dan terhimpun dengan sempurna.

Dalam bidang fiqh, beliau mengemukakan hujjah menolak pendapat yang berdasarkan pemikiran sendiri dan yang tidak sesuai dengan al Quran dan as sunnah. Aliran ini dikenali dengan nama Madzhab Hambali. Imam Hanbali pun menekankan semangat anti ar ra'yu (pemikiran atau filsafat dengan landasan logik). ${ }^{16}$

Dalam memandang al Quran dan as sunnah sebagai sumber hukum Islam, Imam Ahmad bin Hanbal sependapat dengan gurunya yakni Imam Syafi'i, Imam Ahmad memandang as sunnah memiliki kedudukan yang sama kuat disamping al-Quran, sehingga tidak jarang beliau menyebutkan bahwa sumber hukum Islam itu adalah Nash, tanpa menyebutkan al Quran dahulu ataupun as sunnah dahulu, tetapi yang dimaksud olehnya sebagai Nash adalah al Quran dan as sunnah. ${ }^{17}$

Dalam penafsiran terhadap al Quran, Imam Ahmad benar-benar mementingkan penafsiran yang datangnya dari as sunnah. Adapun sikap beliau dapat diklasifikasikan menjadi tiga :

a) Sesungguhnya dzahir al-Quran tidak mendahulukan as sunnah

Persada, 2011), hlm. 160.

15 Ziaul Haque, "Ahmad ibn Hanbal: The Saint Scholar of Baghdad", terj. Nurul Agustina, Jurnal Studi-Studi Islam al-Hikmah, (Bandung: Yayasan Muthahari, 1992), Maret-Juni, hlm. 96.

16 Huzaemah Tahido Yanggo, Pengantar Perbandingan Madzhab (Jakarta: Gaung Persada, 2011), hlm. 160.

17 Rahmad Syafe'i, Ilmu Ushul Fiqih, (Bandung : Pustaka Setia, 2007), hlm. 53-54.

$164 \mid$ JURNAL LISAN AL-HAL 
b) Hanya Rosulullah SAW saja yang berhak untuk menafsirkan al-Quran, maka tidak ada seorangpun yang berhak untuk menafsirkannya atau mentakwilkannya karena as sunnah telah banyak menafsirkan dan menjelaskan al-Quran.

c) Jika tidak ditemukan penafsiran dari Nabi SAW, (maksudnya adalah as sunnah), maka beliau memakai penafsiran para sahabat, karena merekalah yang menyaksikan turunnya al-Quran dan mendengarkan takwilnya dari Rosulullah. Selain itu, para sahabat dinilai lebih mengetahui as sunnah yang mereka gunakan sebagai penafsir alQuran. ${ }^{18}$

Dalam hal penerimaan terhadap hadith ahad sebagai sumber hukum Islam, Imam Ahmad bin Hanbal dan ulama Hanafiyah menerima hadis ahad sebagai sumber hukum tanpa mensyaratkan sesuatupun, kecuali harus shohih sanadnya sebagaimana Asy-Syafi'i. Bahkan beliau juga menerima hadis mursal, namun lebih mendahulukan fatwa sahabat daripada hadis doif..$^{19}$

Dalam bidang teologi, pemikiran Ahmad bin Hanbal tentang ayatayat mutasyabihat, lebih suka menerapkan pendekatan lafdzi / tekstual daripada pendekatan ta'wil, terutama yang berkaitan dengan sifat-sifat Tuhan dan ayat-ayat mutasyabihat. ${ }^{20} \mathrm{Hal}$ itu terbukti ketika suatu ketika Imam Ahmad bin Hanbal dihadapkan dengan makna hadith Nuzul (yakni Tuhan turun ke langit dunia), rukyah (orang yang beriman melihat tuhan di akhirat) dan hadis tentang telapak kaki Tuhan, Ibnu Hanbal menjawab :

$$
\text { نؤمن بما ونصدقها ولاكيف ولا معنى }
$$

"Kita mengimani dan membenarkannya tanpa mencari penjelasan cara dan maknanya".21

Dari pernyataan diatas tampaknya jelas bahwa Imam Ahmad bersikap menyerahkan/ tafwidh makna-makna ayat dan hadith Mutasyabihat kepada Allah dan Rosul-Nya, dan mensucikan-Nya dari keserupaan dengan makhluk, ia sama sekali tidak mentakwilkan pengertian lahirnya.

Salah satu pemikiran yang dilontarkan adalah tentang status alQuran yang sampai menghantarkannya ke penjara. Yang mana apakah alQuran diciptakan (makhluk) yang karenanya hadith (baru) ataukah tidak

\footnotetext{
18 Ibid., hlm. 54.

19 Ibid.

${ }^{20}$ Abdu Rozak dan Rosihan Anwar, Ilmu kalam, hlm. 112.

21 Ibid.,hlm. 113
} 
diciptakan yang karenanya qodim? Ibnu hambal tidak mau membahas lanjut tentang status al-Quran, ia hanya mengatakan bahwa al-Quran tidak diciptakan, hal ini sejalan dengan pola pikirnya yang menyerahkan ayatayat yang berhubungan dengan sifat Allah kepada Allah dan Rosul-Nya. ${ }^{22}$ Dalam beristinbath hukum, imam Ahmad bin Hanbal menggunakan metode ahlul hadith, ${ }^{23}$ dengan dasar-dasr sebagai berikut:

Pertama, Nash Al Qur-an atau nash hadith. Apabila beliau menghadapi suatu nas\} dari al Qur'an dan dari as sunnah shohihah, maka dalam menetapkan hukum adalah dengan nash tersebut, tidak dengan selainnya. Kedua, Fatwa sebagian Sahabat. Apabila beliau tidak mendapatkan suatu nas\} terang, baik dari al-Qur'an maupun sunnah, barulah menggunakan fatwa dari sahabat yang dirasa tidak ada fatwa lain yang menandinginya. Katanya "itu bukanlah ijma"”. Fatwa sahabat didahulukan daripada akal atau qiyas. Apabila terjadi perbedaan pendapat dikalangan sahabat, maka beliau mengambil pendapat yang lebih dekat dengan bunyi teks al-Qur'an atau hadith dan tidak akan mencari yang lainnya. Akan tetapi bila semuanya tidak jelas, maka beliau tidak akan mengambil kesimpulan apapun.

Ketiga, Hadith Mursal dan Hadith dho'if. Apabila Imam Ahmad tidak mendapatkan dari al Qur'an dan as sunnah yang shahihah dan fatwafatwa para sahabat yang disepakati atau diperselisihkan, maka beliau menetapkan hadith mursal dan hadith dho'if. Yang dimaksud hadith dho'if oleh Imam Ahmad adalah karena beliau membagi hadith dalam dua kelompok: shahih dan dho'if, bukan kepada: shahih, hasan dan dho'if seperti kebanyakan ulama yang lain.

Keempat, Qiyas. Beliau menggunakan qiyas bila sudah dalam keadaan terpaksa karena tidak didapatkan dalam hadith mursal ataupun d\}o'if dan juga fatwa para sahabat. ${ }^{24}$ Terkadang Imam Ahmad menggunakan al Mashalih al Mursalah terutama dalam bidang siyasah. Sebagai contoh Imam Ahmad pernah menetapkan hukum ta'zir terhadap orang yang selalu berbuat kerusakan dan menetapkan hukum had yang lebih berat terhadap orang yang minum khamr pada siang hari di bulan Ramadlan. ${ }^{25}$ hlm. 60

22 Ibid.,hlm. 114.

${ }^{23}$ Tim Penyusun, Pengantar Studi Islam, ( Surabaya : IAIN Ampel PRESS, 2006),

${ }^{24}$ www. blogspot.com "Pemikiran Ahmad bin Hanbal" (22 Oktober 2016), hlm. 8.

${ }^{25}$ Huzaemah Tahido Yanggo, Pengantar Perbandingan Madzhab (Jakarta: Gaung Persada, 2011), hlm. 161.

$166 \mid$ JURNAL LISAN AL-HAL 
Tentang ijma', pendirian Imam Ahmad ini sebenarnya tidak berbeda dengan pendirian Imam Syafi'i, karena Imam Syafi'i sendiri pernah berkata "Barang apa yang belum diketahui ada perselisihan di dalamnya itu belum atau bukan ijma' namanya". Sedangkan Imam Anmad berpendapat bahwa ijma' tidak diakui keberadaannya setelah periode sahabat. Beliau berkata, "apa yang dituduh oleh seseorang tentang ijma' adalah dusta". Beliau bukannya tidak mengakui ijma' setelah periode sahabat, tetapi tidak memungkinkan akan terjadinya. Karena itu beliau lebih berpegang pada qiyas setelah teks al-Qur'an, sunnah dan atsar sahabat. ${ }^{26}$

Imam Hanbali disebut sebagai Imam yang wara' (berhati-hati dan menjaga diri). Imam Ahmad juga berhati-hati dalam menerima pendapat, pemikiran orang, atau logika orang. Ia lebih memilih hadith d\}o'if kalau tidak ada kaitannya dengan halal dan haram. ${ }^{27}$ Kalau ada kaitannya, ia lebih memilih hadith shahih yang kuat. Imam Ahmad juga menolak ijma' kecuali yang dilakukan oleh para sahabat Nabi.

Hadith-hadith Imam Ahmad bin Hanbal banyak diriwayatkan oleh tokoh-tokoh besar dalam ilmu hadith seperti al Bukhari, Muslim, Abu Dawud, 28ibn al Mahdi, al Syafi'i, Abu al Walid, Abd Rozaq, Yahya bin Ma'in, Ali ibn al Madiny dan Husein ibn Mansur. Perawi-perawi hadith diataranya adalah para guru, teman sejawat dan murid-muridnya.

\section{Sekilas Tentang Madzhab Hanbali}

Ada beberapa ulama yang mengikuti jejak langkah Imam Ahmad yang menyebarkan madzhab Hanbali, diantaranya : 1) Muwaquddin Ibnu Qudaamah al Maqdisi yang mengarang kitab Al Mughni, 2) Syamsuddin Ibnu Qudaamah al Maqdisi pengarang Assyarhul Kabiir, 3) Syaikhul Islam Taqiuddin Ahmad Ibnu Taimiyah pengarang kitab terkenal Al Fataawa, dan 4) Ibnul Qaiyim al Jauziy pengarang kitab I'laamul Muwaaqi'in dan Atturuqul Hukmiyyah fis Siyaasatis Syar'iyyah. Ibnu Taimiyah dan Ibnul Qaiyim adalah dua tokoh yang membela dan mengembangkan mazhab Hambali.

Pada Awal perkembangannya, madzhab Hanbali berkembang di Bagdad, ${ }^{29}$ Irak dan Mesir dalam waktu yang sangat lama. Pada abad XII madzhab Hanbali berkembang terutama pada masa pemerintahan Raja

\footnotetext{
26 Ibid., hlm. 8.

27 Huzaemah Tahido Yanggo, Pengantar Perbandingan Madzhab (Jakarta: Gaung Persada, 2011), hlm 162.

${ }^{28}$ www.wikipedia.org"Ahmad bin Hanbal" (21 Oktober 2016), hlm. 4.

${ }^{29}$ www. blogspot.com "Pemikiran Ahmad bin Hanbal" (22 Oktober 2016), hlm. 9.
} 
Abdul Aziz As Su'udi. Dan masa sekarang ini menjadi madzhab resmi pemerintahan Saudi Arabia dan mempunyai penganut terbesar di seluruh Jazirah Arab, Palestina, Siria dan Irak.

Di Indonesia, mazdhab Hanbali yang diamalkan sudah mengalami berkali-kali penafsiran berbanding terbalik dengan akar madzhab tersebut di Baghdad (Iraq) dan Mesir. Namun, yang menyusun madzhab Hanbali secara sistematik adalah Ibnu Taimiyyah ${ }^{30}$ yang dengan karya-karyanya yang menyerang ilmu logika (mantiq).

Pada Abad ke-19, madzhab Hanbali ditafsirkan dan dipopulerkan kembali oleh Muhammad bin Abdul Wahhab dan ajarannya disebut "wahhabiyah". Asalnya, ajaran ini adalah minoritas di Hijaz. Tetapi pada tahun 1920-an, Ibnu Saud yang baru mendirikan Kerajaan Arab Saudi telah menetapkan bahwa ajaran wahhabiyah dan madzhab Hanbali menjadi madzhab resmi Kerajaan Arab Saudi31. Dengan dukungan dana yang kuat dan penemuan minyak di Hijaz, maka ajaran Wahhabiyah (yang berakar pada madzhab Hanbali) mulai menyebar ke seluruh dunia Islam.

\section{Simpulan}

Dari pemaparan tersebut, kita dapat mengetahui bahwa Ahmad bin Hanbal adalah seorang ilmuan hukum yang termasuk paling tekstual dalam memahami Al Qur'an dan sunnah. Kecintaan beliau terhadap sunnah dan hadith Nabi Muhammad SAW, membuat beliau dikenal masyarakat luas sebagai ilmuan hadith daripada ilmuan fiqh. Sebagai pembela hadith Nabi yang sangat gigih, dapat dilihat dari cara-cara yang digunakan dalam memutuskan hukum, yakni tidak menggunakan akal kecuali dalam keadaan yang sangat terpaksa.

Beliau sangat berhati-hati tentang riwayat hadith. Menurut pandangan beliau hadith yang digunakan untuk dasar hukum, tidak akan ada manfaatnya tanpa memiliki riwayat. Dalam bidang teologi, pemikiran Ahmad bin Hanbal tentang ayat-ayat mutasyabihat, lebih suka menerapkan pendekatan lafdzi / tekstual daripada pendekatan ta'wil, terutama yang berkaitan dengan sifat-sifat Tuhan dan ayat-ayat mutasyabihat

\section{DAFTAR PUSTAKA}

Abu Zahrah, Muhammad. Ibn Hanbal, Kairo: Dar al Fikr al Araby, 1997. Al-Hasany, Muhammad ibn Ulwy al-Maliki. al-Minhaj al-Latihf Ushul al-

30 Ibid., hlm. 9.

31 Ibid., hlm. 9.

$168 \mid$ JURNAL LISAN AL-HAL 
Hadis al-Syarif. Jeddah: Matabi' Sahr, 1982.

Asy Syurbasy, Ahmad. Sejarah dan Biografi Empat Imam Madzhab. Jakarta: Amzah, 2008.

Blogspot, Pemikiran Ahmad bin Hanbal. Dalam http://www.blogspot.com, 22 Oktober 2016

Dasuki, Hafidz. Ensiklopedi Islam, Jilid III, Jakarta : Ichtiar baru Van Hoeve, 1993.

Haque, Ziaul. "Ahmad ibn Hanbal: The Saint Scholar of Baghdad". Terj. Nurul Agustina, Jurnal Studi-Studi Islam al-Hikmah. Bandung: Yayasan Muthahari, 1992.

Nippontori, Biografi Imam Ahmad bin Hanbal. Dalam http://www.multiply.com, 21 Oktober 2016.

Tahido Yanggo, Huzaemah. Pengantar Perbandingan Madzhab, Jakarta: Gaung Persada, 2011.

Tim Penyusun, Pengantar Studi Islam, Surabaya : IAIN Ampel PRESS, 2006.

Wikipedia, Ahmad bin Hanbal. Dalam http://www.wikipedia.org, 21 Oktober 2016

Zubair, Abu. Biografi Imam Ahmad bin Hanbal. Dalam http://www.wordpress.com, 22 Oktober 2016. 
"Pemikiran Hukum Imam Ahmad bin Hambal"

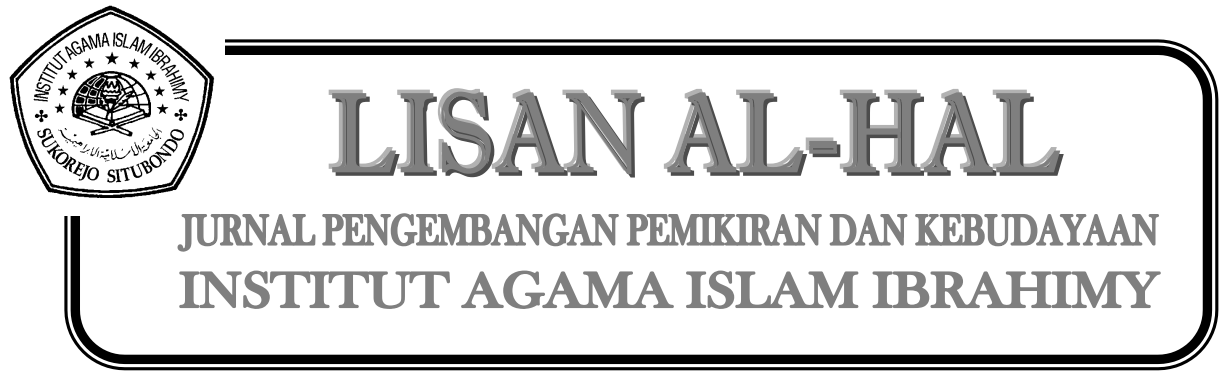

$170 \mid$ JURNAL LISAN AL-HAL 